\title{
The relationship between infancy growth rate and the onset of puberty in both genders
}

\author{
Banu Kucukemre Aydin ${ }^{1}$, Esra Devecioglu², Alev Kadioglu ${ }^{3}$, Ayca Erkin Cakmak ${ }^{4}$, Sezin Kisabacak², Gulbin Gokcay ${ }^{2}$, \\ Firdevs Bas ${ }^{1}$, Sukran Poyrazoglu', Ruveyde Bundak ${ }^{1}$ and Feyza Darendeliler ${ }^{1}$
}

BACKGROUND: In this study, we examined the hypothesis that weight gain and linear growth during the first years of life influence the onset of puberty both in girls and in boys.

METHODS: A cohort of 157 healthy children, aged 6-9 years, was evaluated and their growth patterns were analyzed retrospectively. Repeated measures mixed model was used to examine the longitudinal anthropometric data.

RESULTS: Girls with pubertal signs were heavier than their peers starting at 9 months of age $(P=0.02)$, and the difference became more evident over time $(P<0.001)$. Accelerated weight gain between 6 and 15 months of age was found to increase the odds of having a pubertal sign at the study visit (odds ratio $(\mathrm{OR})=34.5$ ) after adjusting for birth weight, gestational age and current age, height, weight, and BMl $(P=0.004)$. Anthropometric indices of boys with or without pubertal signs were not significantly different at the study visit, but boys with accelerated height gain between 9 and 15 months of age were more likely to have pubertal signs $(\mathrm{OR}=15.8)$ after adjusting for birth weight, gestational age and current age, height, weight, and BMI $(P=0.016)$.

CONCLUSION: Early growth acceleration might be important for the timing of puberty in both genders.

T he onset of puberty has a wide physiological variation based upon a complex interplay between genetic, nutritional, environmental, and socioeconomic factors. One of these determinants is the state of body energy reserves (1). Adequate nutrition is a well-established permissive factor for the normal timing and progression of pubertal development. In 1970, Frisch and Revelle (2) proposed a link between the critical fat mass and the occurrence of menarche. Moreover, extremely low adiposity, as seen with anorexia nervosa or extreme physical activity, is associated with late pubertal timing (3). More recently, the epidemic increase in the prevalence of obesity has received particular attention as a potential etiological factor in early pubertal onset, especially in girls (4). Despite extensive research relating energy balance to puberty, the precise neuroendocrine systems are still only partially known. Furthermore, studies examining body fat and puberty relationship in boys have yielded inconsistent results (5).

Approximately, 25\% of babies show an accelerated weight gain (AWG) during the first two postnatal years (6), and there are studies suggesting that the rate of weight gain during early childhood in girls may influence the timing of puberty (6-8). Although, the biological mechanisms of this condition are not fully discovered yet, it was suggested that AWG during infancy could alter the early hormonal milieu, and program the age of onset and rate of progression through puberty (6). There are few studies relating growth rate to puberty in boys, and the findings are inconsistent $(9,10)$.

In this study, we examined the hypothesis that faster growth during the first years of life may lead to earlier onset of pubertal signs in both genders. To this end, 157 healthy children, aged 6-9 years, were examined, and their growth patterns were evaluated retrospectively.

\section{METHODS}

\section{Subjects}

Our plan was to enroll healthy children as they approached pubertal age. There were 500 eligible children with medical records at the Well Child Clinic of Istanbul University Faculty of Medicine from birth to 5 years of age. Of these, we reached the parents of 220 children by phone call. One hundred and sixty-four children were presented to the clinic for the study visit. We excluded one child with Prader Willi syndrome, two children due to lack of follow-up information, and four children because they were older than age 9 years. The study sample consisted of 157 children (84 girls and 73 boys) with a mean age of $7.6( \pm 0.9)$ years. Age, sex, current BMI, and height and weight $z$-scores (standard deviation scores (SDS)) were not different between those who remained in the final sample and those with missing data $(P$-values $>0.22)$. Only ages were different $(P<0.001)$ for the four children who were excluded because of older age $(P$-values for sex, current BMI SDS, current height SDS, and current weight SDS were $>0.19$ ). The study was approved by the Ethical Committee of Istanbul University Faculty of Medicine and the procedures followed were in accordance with the ethical standards of the institution on human experimentation. Written consent was obtained from the parents.

\footnotetext{
${ }^{1}$ Istanbul Faculty of Medicine, Department of Pediatrics, Pediatric Endocrinology Unit, Istanbul University, Istanbul, Turkey; ${ }^{2}$ Istanbul Faculty of Medicine, Department of Pediatrics, Well Child Unit, Istanbul University, Istanbul, Turkey; ${ }^{3}$ ALKA Radiodiagnostics Center, Istanbul, Turkey; ${ }^{4}$ Department of Pediatrics, Division of Pediatric Endocrinology, University of California San Francisco, San Francisco, California. Correspondence: Banu Kucukemre Aydin (bkucukemre@yahoo.com) 


\section{\begin{tabular}{l|l} 
Infancy growth rate and onset of puberty & Articles
\end{tabular}}

\section{Well Child Clinic Records}

Birth weight (BW), birth length (BL), gestational age, breastfeeding status, parental height, and anthropometric measurements during follow-up were collected from the Well Child Clinic records. Socioeconomic status of the families attending the Well Child Clinic were relatively homogeneous during the study period, as nearly all being white-collar government workers. The routine follow-up schedule included visits at $1,2,3,4,5,6,9,12,15$, and 18 months and every 6 months thereafter until 4 years of age with a final visit at 5 years of age. Because of missing data ( 82 of the 157 children) at the 12 th month visit, the measurements of that age were excluded from the study. There was no scheduled immunization at 12 months of age, which seemed to be the most important reason for the missed visits. At each visit, parents were asked to provide detailed information on the infant's feeding regimen, and a complete physical examination including anthropometric measurements was performed. Length/height and weight were measured by the same two trained nurses over the years. The naked weights were obtained using an electronic digital scale (Seca, 727), accurate to $5 \mathrm{~g}$. A locally manufactured standard measuring board, with increments in millimeters, was used to measure supine length. After 3 years of age, standing height was measured using a Leicester Height Measure (Child Growth Foundation, manufactured by Invicta Plastics Roadby, Leicester, UK).

\section{Study Visit}

Anthropometric measurements and physical examination were performed by the same physician (B.K.A.) for all children in the morning after an overnight fast. Heights were measured in the standing position with bare feet, using Harpenden equipment, and an electronic scale sensitive to $0.1 \mathrm{~kg}$ was used for weight measurements, which were conducted with the children in their minimal underclothes. Waist circumference (WC) was measured midway between the costal border and the iliac crest to the nearest millimeter using a Seca measuring tape (Germany). Height and WC measurements were repeated twice, and the mean value was calculated. Children were evaluated for puberty according to Tanner classification $(11,12)$, breast development was assessed by both inspection and palpation to avoid misclassification of fat tissue as breast development, and testicular volume was assessed using a Prader orchidometer (China). Pubertal signs were defined as attaining breast stage 2 or greater in girls, a testicular volume $\geq 4 \mathrm{ml}$ in boys, and Tanner stage 2 pubic hair in both. If a girl had a larger breast on one side, the larger stage was used, and likewise, if testicular volumes were not equal, the larger testis measurement was used. Although the first physical sign of puberty is breast development in most, pubic/axillary hair development occurs before thelarche in a minority of girls (13-15). Likewise, the first marker for the pubertal onset is testicular growth in majority of boys, but development of pubic/axillary hair would be the first sign $(15,16)$. Previous studies suggest a pathway in which the onset of puberty is preceded by increased androgen levels, as a result of peripheral conversion of androgens into estrogens, and/or hypothalamopituitary maturation or other as yet undiscovered mechanisms (17). We believe that the order of pubertal signs would differ due to adiposity level, aromatase activity, and tissue hormone sensitivity, so we did most of the analyses using all the pubertal signs together to increase the power for statistical analyses. Furthermore, we examined each pubertal sign separately. All children with pubertal signs were referred to the Pediatric Endocrinology clinic for further evaluation with stimulation tests, bone age assessments, and imaging studies when needed, and no additional clinical illness was detected (e.g., organic brain lesions, non-classical congenital adrenal hyperplasia, or other adrenal/ovarian pathologies).

\section{Laboratory Evaluation}

Venous blood samples were collected for LH, FSH, and estradiol (E2) in girls, and testosterone (T) in boys, at the study visit. Samples were immediately processed and sera were stored at $-80^{\circ} \mathrm{C}$ for subsequent batch analysis. LH levels were measured by DSL-4600 Active LH-coated tube immunoradiometric assay (IRMA, Diagnostic Systems Laboratories, Webster, TX) the limit of detection was $0.12 \mathrm{mIU} / \mathrm{ml}$ with an intra- and inter-assay cutoff value $(\mathrm{CV})$ of 4.8 $-8.9 \%$ and $6.8-8.9 \%$, respectively. FSH levels were measured by DSL-4700 Active FSH-coated tube IRMA (IRMA, Diagnostic Systems Laboratories) with an intra- and inter-assay CV of $1.6-$ $3.6 \%$ and $5.6-7.7 \%$, respectively and the limit of detection was $0.11 \mathrm{mIU} / \mathrm{ml}$. E2 levels were measured by electrochemiluminescence immunoassay (ECLIA, Cobas e 601 analyzer, Roche Diagnostics, Indianapolis, IN) kits with intra- and inter-assay CV of $1.3-6.1 \%$ and $1.9-7.0 \%$, respectively, and the functional sensitivity was $12 \mathrm{pg} / \mathrm{ml}$. $\mathrm{T}$ levels were measured by DSL-4000 Active T-coated tube radioimmunoassay (RIA, Diagnostic Systems Laboratories) kits with intra- and inter-assay CV of $7.8-9.6 \%$ and $8.4-9.1 \%$, respectively, and the limit of detection was $0.08 \mathrm{ng} / \mathrm{ml}$. Pelvic ultrasounds (USG) were performed by the same radiologist (A.K.), who was blinded to the clinical and laboratory findings, using a Siemens S2000 scanner (Siemens Medical Solutions, Mountain View, CA) and a $4-\mathrm{MHz}$ convex probe. Right and left ovarian volumes, uterine maximum diameter, uterine volume, endometrial thickness, and fundus/cervix ratio were recorded.

\section{Calculations and Definitions}

BW and BL national standards for gestational age were used and $z$ scores were calculated (18). Ponderal index was calculated as BW (g)/ $[\mathrm{BL}(\mathrm{cm})]^{3} \times 100$. BMI was calculated as weight $(\mathrm{kg}) /[\text { height }(\mathrm{m})]^{2}$. Height, weight, and BMI were expressed as SDS according to the national standards for each visit between 1 and 60 months of age (19). Growth velocity, change in height SDS ( $\Delta$ height SDS), weight SDS ( $\Delta$ weight SDS), and BMI SDS ( $\Delta$ BMI SDS) were calculated for each 3-6 month interval between 0 and 36 months. AWG was defined as a gain of weight $\geq 0.67$ SDS and accelerated height gain (AHG) was defined as a gain of height $\geq 0.67$ SDS. This cutoff point was defined in previous studies and was sufficient to result in an upward centile crossing on clinical growth charts (20). Height, weight, BMI, and WC SDS values at the time of the study were calculated according to the national standards (21-23). Ovarian and uterine volumes were expressed as SDS, calculated according to the subject's age (24). Overweight was defined as a BMI SDS $\geq 1$ and obesity was defined as $\geq 2$ SDS. Small for gestational age (SGA) was defined as BW less than or equal to -1.88 SDS.

\section{Data Analyses}

Data were presented as the mean $\pm \mathrm{SD}$. The clinical and laboratory parameters of children with and without pubertal findings were compared using the Mann-Whitney $U$-test. Chi-square test was used for categorical variables. Girls and boys were evaluated separately. We used Spearman analysis to determine correlations between anthropometric measures and pubertal signs. Repeated measures mixed model was used to examine the longitudinal anthropometric data between prepubertal and pubertal children. We created separate multivariate logistic regression models to examine associations between pubertal signs and accelerated early growth in boys and girls. We adjusted the models for BW SDS, gestational age and current age, height, weight, and BMI SDSs. All statistical analyses were conducted with STATA version 12.1 (Stata, College Station, TX). Statistical significance was defined as $P \leq 0.05$.

\section{RESULTS}

There was no age difference between the boys and girls $(7.6 \pm 1.0$ and $7.5 \pm 0.9$ years, $P=0.74)$ at the time of the study visit, of which $45 \%$ (38/84) of girls and $20.5 \%$ (15/73) of boys had pubertal signs. Thirty-two girls $(38.1 \%)$ had breast development, seventeen (20.2\%) had pubic/axillary hair, and eleven $(13 \%)$ had synchronous breast and pubic/axillary hair development. Nine boys (12.3\%) had testicular volume 
$\geq 4 \mathrm{ml}$, eight boys (11\%) had pubic/axillary hair, and two boys (2.7\%) had synchronous pubertal development. Thirty-one girls (36.9\%) and twenty-eight boys (38.4\%) were found to be overweight or obese at the study visit, and these rates were not different between the genders $(P=0.85)$.

Table 1 presents the clinical and laboratory characteristics of girls with and without pubertal signs. Girls with pubertal signs were older, taller, heavier, and had significantly higher BMI and WC SDSs. They were also more often overweight or obese $(55.2 \%$ vs. $21.7 \%)$ at the time of study visit. Target height SDS was also higher in those girls. Gestational age was slightly lower in girls with pubertal signs, but BW and $\mathrm{BL}$ SDSs and ponderal index were not significantly different. In our study group, only one girl was born before 37 weeks of gestation and she was prepubertal. Of the two SGA-born girls, one had no pubertal signs and the other had stage 2 breast development. Basal LH levels and ovarian volume SDS were higher in girls with pubertal signs, but FSH and E2 levels were not significantly different.

Table 2 compares clinical and laboratory characteristics in boys with and without pubertal signs. Prepubertal boys were younger, but no significant difference was found in any of the anthropometric measurements at the study visit. Although BW and BL SDSs were not significantly different, Ponderal index was higher in the prepubertal boys. There were no SGA-born boys in our study group. Boys with pubertal signs had significantly higher exclusive breastfeeding time, but no significant difference was found for total breastfeeding time. Basal LH levels were significantly higher in boys with pubertal signs, but FSH and T levels were not different.

\section{Correlation Analyses}

There were positive correlations between breast stage and age ( $r=0.37, P=0.001)$, height $(r=0.29, P=0.007)$, weight $(r=0.38, P<0.001)$, and BMI SDSs $(r=0.33, P=0.002)$ of girls at the study visit. In addition, $\mathrm{LH}$ and E2 levels were positively correlated with breast stage $(r=0.52, P<0.001$; and $r=0.25, P=0.035$, respectively) and breast stages were also correlated with mean ovarian $(r=0.30, P=0.025)$ and uterine $(r=0.30, \quad P=0.028)$ volume. E2 levels were positively correlated with weight SDS at the study visit $(r=0.27$, $P=0.022)$.

No significant correlation was found between the testis volume and age and anthropometric parameters at the study visit in boys (data not shown). The testis volumes were positively correlated with LH levels ( $r=0.51, P=0.009)$, but no significant correlation was found with $\mathrm{T}$ levels $(r=0.29$, $P=0.14)$.

\section{Analysis of Early Growth Data}

Evaluation of early growth parameters revealed that girls with pubertal signs had higher weight SDS values than the girls without pubertal signs starting from 9 months of age $(P=0.02)$, which became more evident over time $(P=<0.001$, Figure 1a). Beginning between 6 and 9 months of age, the weight of girls with pubertal signs
Table 1. Comparison of the clinical and laboratory characteristics of girls according to their pubertal status ${ }^{a}$

\begin{tabular}{|c|c|c|c|}
\hline & $\begin{array}{l}\text { Without pubertal } \\
\text { signs }(n=46)\end{array}$ & $\begin{array}{l}\text { With pubertal } \\
\text { signs }(n=38)\end{array}$ & $P$ \\
\hline Birth weight SDS & $0.2 \pm 1.2$ & $0.5 \pm 1.4$ & 0.32 \\
\hline Birth length SDS & $-0.3 \pm 1.0$ & $0.04 \pm 0.9$ & 0.11 \\
\hline Ponderal index & $2.81 \pm 0.30$ & $2.78 \pm 0.27$ & 0.43 \\
\hline $\begin{array}{l}\text { Gestational age } \\
\text { (weeks) }\end{array}$ & $39.2 \pm 1.3$ & $38.7 \pm 0.9$ & 0.009 \\
\hline $\begin{array}{l}\text { Exclusive } \\
\text { breastfeeding time } \\
\text { (months) }\end{array}$ & $5.1 \pm 1.6$ & $5.1 \pm 1.8$ & 0.51 \\
\hline $\begin{array}{l}\text { Total breastfeeding } \\
\text { time (months) }\end{array}$ & $15.0 \pm 6.4$ & $12.6 \pm 4.9$ & 0.10 \\
\hline Target height SDS & $-0.4 \pm 0.7$ & $0.0 \pm 0.9$ & 0.05 \\
\hline
\end{tabular}

$\begin{array}{lrrr}\text { Recent clinical and laboratory findings } & & \\ \text { Age (years) } & 7.2 \pm 0.9 & 7.9 \pm 0.8 & \mathbf{0 . 0 0 1} \\ \text { Height SDS } & 0.2 \pm 0.9 & 0.9 \pm 1.1 & \mathbf{0 . 0 0 3} \\ \text { Weight SDS } & 0.3 \pm 1.0 & 1.3 \pm 1.3 & <\mathbf{0 . 0 0 1} \\ \text { BMI SDS } & 0.3 \pm 1.0 & 1.1 \pm 1.2 & \mathbf{0 . 0 0 1} \\ \text { Waist } & 0.3 \pm 1.3 & 1.1 \pm 1.6 & \mathbf{0 . 0 4} \\ \text { circumference SDS } & & & \\ \begin{array}{l}\text { Obese and } \\ \text { overweight } n(\%)\end{array} & 10(21.7) & 21(55.2) & \mathbf{0 . 0 0 2} \\ \text { LH (mIU/ml) } & 0.2 \pm 0.1 & 0.3 \pm 0.2 & \mathbf{0 . 0 0 6} \\ \text { FSH (mlU/ml) } & 1.5 \pm 0.6 & 1.8 \pm 1.0 & 0.32 \\ \text { Estradiol }(\mathrm{pg} / \mathrm{ml}) & 12.5 \pm 14.3 & 13.0 \pm 13.5 & 0.21\end{array}$

Pelvic ultrasonography findings

$\begin{array}{lccc}\begin{array}{l}\text { Mean ovarian } \\ \text { volume SDS }\end{array} & -0.2 \pm 1.0 & 1.2 \pm 3.7 & \mathbf{0 . 0 4} \\ \begin{array}{l}\text { Uterine maximum } \\ \text { diameter (mm) }\end{array} & 31.1 \pm 5.1 & 32.3 \pm 4.8 & 0.44 \\ \text { Uterine volume SDS } & -0.9 \pm 0.7 & -0.7 \pm 0.7 & 0.39 \\ \begin{array}{l}\text { Fundus/cervix ratio } \\ \text { Endometrial }\end{array} & 1.0 \pm 0.4 & 1.0 \pm 0.2 & 0.12 \\ \text { thickness (mm) } & 1.4 \pm 0.4 & 1.7 \pm 0.6 & 0.08\end{array}$

FSH, follicle stimulating hormone; LH, luteinizing hormone.

${ }^{a}$ All values are means \pm SDs, except if otherwise stated.

Bold text indicates a statistically significant difference with a p-value less than 0.05 .

began to diverge from that of the girls who remained prepubertal at the study visit $(P=0.003$, Figure 1a). Between 9 and 15 months of age, girls with pubertal signs continued to gain more weight and their $\Delta$ weight SDS 6-15 months was significantly higher than the girls without pubertal signs $(P=0.006$, Figure 1a).

To further understand the evident relationship between early weight gain and puberty, girls with AWG between 6 and 15 months of age were identified; there were 12 girls with AWG in 33 pubertal girls (36\%) and 3 in 38 prepubertal girls (7.9\%) $(P=0.003)$. Moreover, girls with AWG were far more likely to be pubertal at the time of study visit (odds ratio 


\section{Infancy growth rate and onset of puberty Articles}

Table 2. Comparison of the clinical and laboratory characteristics of boys according to their pubertal status ${ }^{a}$

\begin{tabular}{lccc}
\hline & $\begin{array}{c}\text { Without pubertal } \\
\text { signs }(n=58)\end{array}$ & $\begin{array}{c}\text { With pubertal } \\
\text { signs }(n=15)\end{array}$ & $P$ \\
\hline Birth weight SDS & $0.3 \pm 0.9$ & $0.1 \pm 0.9$ & 0.35 \\
Birth length SDS & $-0.3 \pm 1.2$ & $0.0 \pm 0.6$ & 0.51 \\
$\begin{array}{l}\text { Ponderal index } \\
\text { Gestational age }\end{array}$ & $2.86 \pm 0.32$ & $2.68 \pm 0.25$ & $\mathbf{0 . 0 4}$ \\
(weeks) & $38.8 \pm 1.8$ & $38.4 \pm 1.4$ & 0.32 \\
$\begin{array}{l}\text { Exclusive } \\
\text { breastfeeding time } \\
\text { (months) }\end{array}$ & $4.4 \pm 2.4$ & $6.0 \pm 0.0$ & $\mathbf{0 . 0 0 5}$ \\
$\begin{array}{l}\text { Total breastfeeding } \\
\text { time (months) }\end{array}$ & $14.6 \pm 7.1$ & $16.9 \pm 5.8$ & \\
Target height SDS & $-0.1 \pm 0.9$ & $-0.3 \pm 0.7$ & 0.64
\end{tabular}

Recent clinical and laboratory findings

\begin{tabular}{|c|c|c|c|}
\hline Age (years) & $7.5 \pm 0.9$ & $8.1 \pm 0.8$ & 0.01 \\
\hline Height SDS & $0.7 \pm 1.2$ & $1.1 \pm 1.2$ & 0.19 \\
\hline Weight SDS & $1.0 \pm 1.7$ & $1.4 \pm 1.2$ & 0.14 \\
\hline BMI SDS & $0.9 \pm 1.6$ & $1.1 \pm 1.3$ & 0.26 \\
\hline $\begin{array}{l}\text { Waist circumference } \\
\text { SDS }\end{array}$ & $0.8 \pm 1.8$ & $1.1 \pm 1.3$ & 0.25 \\
\hline $\begin{array}{l}\text { Obese and } \\
\text { overweight } n(\%)\end{array}$ & $21(36.2)$ & 7 (46.7) & 0.46 \\
\hline LH (mlU/ml) & $0.1 \pm 0.1$ & $0.3 \pm 0.1$ & 0.01 \\
\hline $\mathrm{FSH}(\mathrm{mlU} / \mathrm{ml})$ & $0.8 \pm 0.5$ & $0.7 \pm 0.4$ & 0.40 \\
\hline Testosterone (ng/ml) & $0.1 \pm 0.1$ & $0.1 \pm 0.1$ & 0.74 \\
\hline
\end{tabular}

$(\mathrm{OR})=34.5,95 \%$ confidence interval (CI) 3.1-388.8 ) after adjusting for BW SDS, gestational age and current age, height, weight, and BMI SDSs $(P=0.004)$. Furthermore, girls with AWG between 6 and 15 months of age had shorter exclusive $(3.7 \pm 2.3$ vs. $5.4 \pm 1.4$ months, $P=0.001)$ and total $(10.5 \pm 4.6$ vs. $15.3 \pm 5.8$ months, $P=0.007)$ breastfeeding times than did girls without AWG.

Height SDS values during the follow-up were not significantly different between girls with and without pubertal signs, but $\Delta$ height SDS 6-15 months was significantly higher in girls with pubertal signs $(P=0.04$, Figure $1 \mathbf{b})$. BMI SDS was significantly higher in girls with pubertal signs starting at 15 months of age $(P=0.046)$ and as with body weight, the difference persisted and became more pronounced as the girls grew older $(P<0.001$, Figure 1c).

For boys, an evaluation of early growth parameters revealed no significant difference between the weight SDS values of boys with or without pubertal signs (Figure 2a); however, boys with pubertal signs had a significant BMI SDS increment between 6 and 9 months of age $(P=0.03$, Figure 2c), and following that period, between 9 and 15 months of age there was a significant height SDS increment along with BMI SDS decrement in those boys $(P=0.002$ and $P=0.001$,
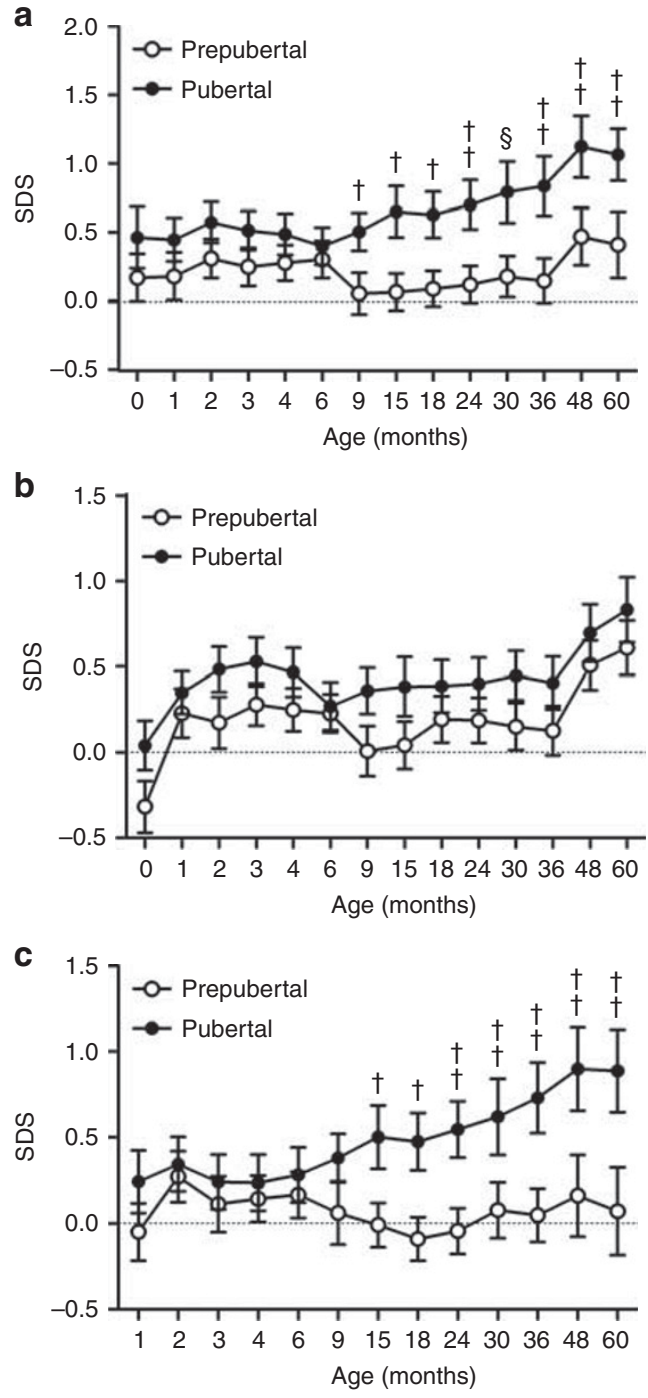

Figure 1. Changes in anthropometric measurements during the first 60 months of life in girls with and without pubertal signs, (a) weight, (b) height, and (c) BMI SDS values (mean \pm SEM) $\left({ }^{\dagger} P<0.05,{ }^{\ddagger} P<0.01\right.$, ${ }^{\S} P<0.001$ ). (Repeated measures mixed model was used to examine the longitudinal anthropometric data).

respectively) (Figure 2b,c). Moreover, boys with AHG between 9 and 15 months of age were more likely to have a pubertal sign at the study visit $(O R=15.8)$ after adjusting for BW SDS, gestational age and current age, height, weight, and BMI SDS $(P=0.016)$. There was no significant difference between exclusive and total breastfeeding times of the boys with or without AHG between 9 and 15 months of age (data not shown).

\section{Evaluation of Pubertal Signs Separately}

Evaluation of longitudinal growth data showed that girls with breast development had higher weight and BMI SDS values than the girls without breast development starting at 9 months of age, but differences only reached statistical significance at 18 months of age for weight SDS and BMI SDS $(P=0.05$ and $P=0.05)$ and at the study visit for weight SDS, height SDS, 

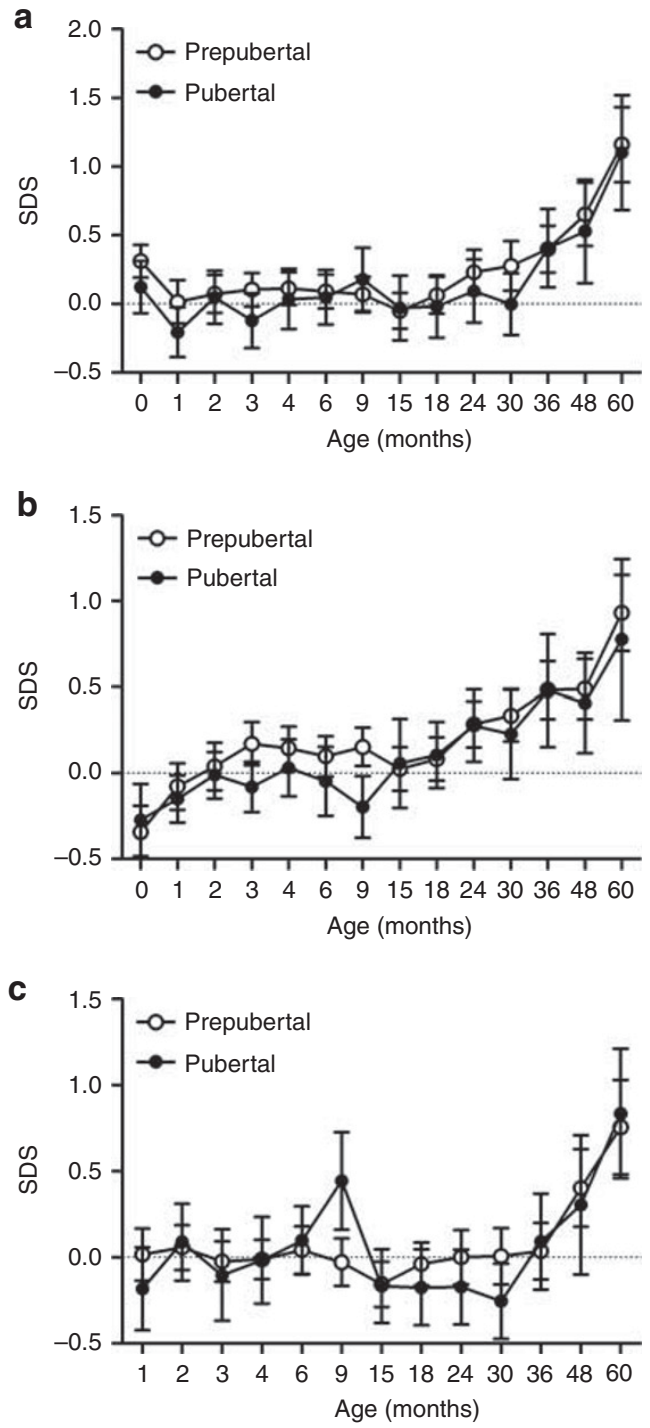

Figure 2. Changes in anthropometric measurements during the first 60 months of life in boys with and without pubertal signs, (a) weight, (b) height, and (c) BMI SDS values (mean \pm SEM). (Repeated measures mixed model was used to examine the longitudinal anthropometric data).

and BMI SDS $(P=0.001, P=0.01$, and $P=0.002$, respectively). Additionally, girls with breast development were more likely to have AWG between 6 and 15 months of age $(P=0.05)$.

Girls with pubic/axillary hair had also similar trends in their early growth trajectories, but the differences were statistically significant for weight SDS at $9,15,18,24$, and 36 months of ages and at the study visit $(P=0.02, P=0.002, P=0.02$, $P=0.04, P=0.03$, and $P=0.02$, respectively) and for BMI SDS at 9,15 , and 36 months of ages and at the study visit ( $P=0.02, P=0.003, P=0.03$, and $P=0.04$, respectively). In addition, girls with pubic/axillary hair had higher height SDS at the study visit $(P=0.04)$.

Boys with pubic/axillary hair at the study visit were more likely to have AHG between 9 and 15 months of age $(P=0.006)$.

\section{DISCUSSION}

The association between higher BMI and earlier onset of puberty in girls was reported before (25), but the direction of this association and the underlying mechanisms were not clear. We observed that the girls with early puberty were already heavier than their peers starting from 9 months of age, as well as girls with AWG in infancy were more likely to enter puberty earlier. Previous studies investigating the relationship between puberty and excessive weight gain during early childhood have mainly focused on the timing of menarche, a relatively late pubertal milestone, which is also associated with duration of puberty $(7,26-28)$. Additionally, data on growth in infancy and early childhood were derived from various clinic recordings and home settings, so their accuracy is uncertain. Moreover, most of the studies did not include growth data between birth and 2 years of age. Davison et al. (29) showed that girls with higher percent body fat at age 5 years, and girls with higher percent body fat, higher BMI percentile, or larger WC at age 7 years were more likely to be pubertal at 9 years of age. In this study pubertal development was assessed using visual inspection of the breast tissue, Pubertal Development Scale and estradiol levels. Lee et al. (30) found that higher BMI $z$-score in girls at 36 months of age and a greater rate of change of BMI between age 36 months and school grade 1were associated with earlier puberty. Assessment of pubertal stages was done by physical examination and/or maternal report, in this study.

In our study, infancy growth rate was shown to affect pubertal timing in boys; however, there was no significant difference in height, weight, or BMI of boys with or without pubertal signs at the time of pubertal evaluation. Similar to our results, there are some studies suggesting that a relationship does exist between pubertal timing and early growth in boys, but various and mostly late pubertal markers were used in those studies $(9,27,31,32)$ and some studies reported conflicting results. Hui et al. (33) reported that compared with boys of average BW whose weight growth followed similar percentile to birth weight, boys born heavy who grew fast had the youngest age at pubertal onset. In this study, pubertal maturation status was only visually assessed by different doctors according to the criteria of Marshall and Tanner. Wang et al. (34) found that boys with greater early weight gains were younger when they reached advanced Tanner stages, but few of these effects were statistically significant. In this study, pubertal development was evaluated using a selfreport questionnaire. On the other hand, Lee et al. (10) reported that boys in the highest BMI trajectory from ages 2 to 11.5 years had a greater relative risk of being prepubertal compared with boys in the lowest BMI trajectory. Assessment of pubertal stages was done by visual inspection using Tanner genitalia staging.

The underlying mechanism of the relationship between pubertal timing and growth rate in infancy is not known precisely. Overlap of genes involved in pubertal timing and adiposity from genome-wide association studies (GWAS) suggest the existence of a pathway connecting early childhood 


\section{Infancy growth rate and onset of puberty $\mid$ Articles}

weight gain and earlier pubertal timing, particularly in girls (17). Increased adiposity may lead to increased insulin levels, adrenal steroids, and aromatase activity, as well as decreased sex-hormone-binding globulin levels, and eventually increased sex steroid bioavailability in prepubertal years (35). Additionally, AWG in early childhood may increase leptin levels and leptin is thought to have a permissive role in the onset of puberty, especially in girls, allowing puberty to proceed only when metabolic conditions are sufficient (17).

Early puberty is associated with adverse health outcomes, including breast and endometrial cancer, adult obesity, type 2 diabetes, and cardiovascular disease (CVD) risk (36), but the exact mechanisms underlying this association are not known. Barker hypothesis, the developmental origin of health and disease, is based on the observation that low birth weight children are at increased risk for metabolic and CVD as adults. SGA children are programmed to store as much energy as possible, causing AWG in infancy. Most of the wellknown risks for CVD and earlier puberty were attributed to this catch-up growth, in SGA children (37). Girls with early pubertal signs in our study group were not SGA by classical definition; however, they had AWG in late infancy, simulating a catch-up growth. We think that our findings support the idea that adiposity beginning in infancy may contribute to the relationship between adverse health outcomes and early puberty in girls.

We found that girls with AWG between 6 and 15 months of age had shorter exclusive and total breastfeeding times than did their peers. Our results were in accordance with the previous studies in which infant formulas were proposed to predispose them to AWG in infancy (38). In a recent study, Kale et al. (39) reported that girls who were mixed-fed or predominantly breastfed had later onset of breast development than formula-fed girls, and that the duration of breastfeeding was directly related to the age at onset of breast development.

Unexpectedly, boys with early pubertal signs had longer exclusive breastfeeding times. When we evaluated their growth trajectories, we realized that after 6 months of age, with the introduction of solid foods, boys with early puberty had a significant BMI increment, seeming like a catch-up growth, which was followed by a profound height gain between 9 and 15 months of age. Height gain and bone maturation are closely linked to the timing of puberty and the tempo of linear growth is mostly established within the first 2 years of life, with greater weight gain being associated with a more rapid tempo of height gain (6). Furthermore, poor weight gain is associated with a delayed growth and, most often with delayed puberty.

Although many studies have focused on the relationship between being born SGA and early puberty, only a few have investigated the possible relationship between preterm birth and pubertal timing. In our study, gestational age was slightly lower in girls with pubertal signs, but a vast majority of our subjects were full term. Contradictory to our results, Hui et al. (40) reported that premature birth was related to later onset of puberty among girls.

The obesity epidemic was suggested as the major reason for earlier puberty in girls in recent years, but many authors disagreed due to difficulties in detecting breast tissue in obese children. We examined breast tissue by palpation and found higher LH levels as well as higher ovarian volumes by USG in girls with pubertal signs. In addition, LH and E2 levels and mean ovarian and uterine volumes were positively correlated with breast stage. Another strength of our study is the good quality of our early growth data as being based on anthropometric measurements of a single center. Previous studies have described socioeconomic and ethnic/racial patterning of the onset of puberty. Socioeconomic circumstances and ethnicity were suggested to be linked to increased adiposity and psychosocial stress (41). Our study group was relatively homogeneous in socioeconomic status as well as ethnicity. However, this study has several limitations. Owing to the small number of children with pubertal signs, particularly boys, we might have missed some of the growth patterns during infancy. The high rates of overweight-obesity and early puberty in our study population may be partly due to a selection bias, as parents whose children were obese or had pubertal signs might have been more willing to participate in this research. Finally, we did not use HPLCMS, a more sensitive technique for steroid hormone analyses.

In conclusion, girls with pubertal signs had higher weight than their peers starting at 9 months of age, and AWG between 6 and 15 months was shown to affect pubertal timing independent of recent BMI in girls. Anthropometric measurements of boys with or without pubertal signs were not significantly different, but AHG after 9 months of age was found to affect pubertal timing in boys. These results suggested that early growth acceleration is important for the timing of puberty in both sexes, but girls and boys showed different growth patterns that need to be evaluated in further studies.

\section{ACKNOWLEDGMENTS}

We are immensely grateful to Stephen J. Winters, MD, Professor of Medicine for his valuable comments on earlier versions of the manuscript.

\section{STATEMENT OF FINANCIAL SUPPORT}

This study was supported by Scientific Research Projects Coordination Unit of Istanbul University (Project Number: 24280).

Disclosure: The authors declare no conflict of interest.

\section{REFERENCES}

1. Roa J, Garcia-Galiano D, Castellano JM, Gaytan F, Pinilla L, Tena-Sempere M. Metabolic control of puberty onset: new players, new mechanisms. Mol Cell Endocrinol 2010;324:87-94.

2. Frisch RE, Revelle R. Height and weight at menarche and a hypothesis of critical body weights and adolescent events. Science 1970;169:397-9.

3. Munoz MT, Argente J. Anorexia nervosa in female adolescents: endocrine and bone mineral density disturbances. Eur J Endocrinol 2002;147: 275-86.

4. Herman-Giddens ME, Slora EJ, Wasserman RC, et al. Secondary sexual characteristics and menses in young girls seen in office practice: a study 
from the Pediatric Research in Office Settings network. Pediatrics 1997;99:505-12.

5. Lee JM, Wasserman R, Kaciroti N, et al. Timing of puberty in overweight versus obese boys. Pediatrics 2016;137:1-10.

6. Dunger DB, Ahmed ML, Ong KK. Early and late weight gain and the timing of puberty. Mol Cell Endocrinol 2006;254-255:140-5.

7. dos Santos Silva I, De Stavola BL, Mann V, et al. Prenatal factors, childhood growth trajectories and age at menarche. Int J Epidemiol 2002;31:405-12.

8. Papadimitriou A, Beri D, Tsialla A, et al. Early growth acceleration in girls with idiopathic precocious puberty. J Pediatr 2006;149:43-6.

9. He Q, Karlberg J. BMI in childhood and its association with height gain, timing of puberty, and final height. Pediatr Res 2001;49:244-51.

10. Lee JM, Kaciroti N, Appugliese D, et al. Body mass index and timing of pubertal initiation in boys. Arch Pediatr Adolesc Med 2010;164: $139-44$.

11. Marshall WA, Tanner JM. Variations in pattern of pubertal changes in girls. Arch Dis Child 1969;44:291-303.

12. Marshall WA, Tanner JM. Variations in the pattern of pubertal changes in boys. Arch Dis Child 1970;45:13-23.

13. Biro FM, Huang B, Daniels SR, et al. Pubarche as well as thelarche may be a marker for the onset of puberty. J Pediatr Adolesc Gynecol 2008;21: $323-8$.

14. Christensen KY, Maisonet M, Rubin C, et al. Progression through puberty in girls enrolled in a contemporary British cohort. J Adolesc Health 2010;47:282-9.

15. Wohlfahrt-Veje C, Korsholm Mouritsen A, Hagen CP, et al. Pubertal onset in boys and girls is influenced by pubertal timing of both parents. J Clin Endocrinol Metab 2016;101:2667-74.

16. Biro FM, Lucky AW, Huster GA, et al. Pubertal staging in boys. J Pediatr 1995;127:100-2.

17. Willemsen RH, Dunger DB. Normal variation in pubertal timing: genetic determinants in relation to growth and adiposity. Endocr Dev 2016;29: $17-35$.

18. Kurtoglu S, Hatipoglu N, Mazicioglu MM, et al. Body weight, length and head circumference at birth in a cohort of Turkish newborns. J Clin Res Pediatr Endocrinol 2012;4:132-9.

19. Gokcay G, Furman A, Neyzi O. Updated growth curves for Turkish children aged 15 days to 60 months. Child Care Health Dev 2008;34: 454-63.

20. Ekelund U, Ong KK, Linne Y, et al. Association of weight gain in infancy and early childhood with metabolic risk in young adults. J Clin Endocrinol Metab 2007;92:98-103.

21. Neyzi O, Furman A, Bundak R, et al. Growth references for Turkish children aged 6 to 18 years. Acta Paediatr 2006;95:1635-41.

22. Bundak R, Furman A, Gunoz H, et al. Body mass index references for Turkish children. Acta Paediatr 2006;95:194-8.
23. Hatipoglu N, Ozturk A, Mazicioglu MM, et al. Waist circumference percentiles for 7- to 17-year-old Turkish children and adolescents. Eur J Pediatr 2008;167:383-9.

24. Orsini LF, Salardi S, Pilu G, et al. Pelvic organs in premenarcheal girls: real-time ultrasonography. Radiology 1984;153:113-6.

25. Biro FM, Greenspan LC, Galvez MP, et al. Onset of breast development in a longitudinal cohort. Pediatrics 2013;132:1019-27.

26. Ong KK, Emmett $\mathrm{P}$, Northstone $\mathrm{K}$, et al. Infancy weight gain predicts childhood body fat and age at menarche in girls. J Clin Endocrinol Metab 2009;94:1527-32.

27. Karaolis-Danckert N, Buyken AE, Sonntag A, et al. Birth and early life influences on the timing of puberty onset: results from the DONALD (DOrtmund Nutritional and Anthropometric Longitudinally Designed) Study. Am J Clin Nutr 2009;90:1559-65.

28. Terry MB, Ferris JS, Tehranifar P, et al. Birth weight, postnatal growth, and age at menarche. Am J Epidemiol 2009;170:72-9.

29. Davison KK, Susman EJ, Birch LL. Percent body fat at age 5 predicts earlier pubertal development among girls at age 9. Pediatrics 2003;111: 815-21.

30. Lee JM, Appugliese D, Kaciroti N, et al. Weight status in young girls and the onset of puberty. Pediatrics 2007;119:e624-30.

31. Ong KK, Bann D, Wills AK, et al. Timing of voice breaking in males associated with growth and weight gain across the life course. J Clin Endocrinol Metab 2012;97:2844-52.

32. Boyne MS, Thame M, Osmond C, et al. Growth, body composition, and the onset of puberty: longitudinal observations in Afro-Caribbean children. J Clin Endocrinol Metab 2010;95:3194-200.

33. Hui LL, Wong MY, Lam TH, et al. Infant growth and onset of puberty: prospective observations from Hong Kong's "Children of 1997" birth cohort. Ann Epidemiol 2012;22:43-50.

34. Wang Y, Dinse GE, Rogan WJ. Birth weight, early weight gain and pubertal maturation: a longitudinal study. Pediatr Obes 2012;7:101-9.

35. Aydin B, Winters SJ. Sex hormone-binding globulin in children and adolescents. J Clin Res Pediatr Endocrinol 2016;8:1-12.

36. Golub MS, Collman GW, Foster PM, et al. Public health implications of altered puberty timing. Pediatrics 2008;121:S218-30.

37. Roth CL, DiVall S. Consequences of early life programing by genetic and environmental influences: a synthesis regarding pubertal timing. Endocr Dev 2016;29:134-52.

38. Lifschitz C. Early life factors influencing the risk of obesity. Pediatr Gastroenterol Hepatol Nutr 2015;18:217-23.

39. Kale A, Deardorff J, Lahiff M, et al. Breastfeeding versus formula-feeding and girls' pubertal development. Matern Child Health J 2015;19:519-27.

40. Hui LL, Leung GM, Lam TH, et al. Premature birth and age at onset of puberty. Epidemiology 2012;23:415-22.

41. Kelly Y, Zilanawala A, Sacker A, et al. Early puberty in 11-year-old girls: Millennium Cohort Study findings. Arch Dis Child 2017;102:232-7. 